\title{
Evaluation of the antioxidant peptide SS31 for treatment of burn-induced insulin resistance
}

\author{
EDWARD A. CARTER ${ }^{2,4,5}$, ALI A. BONAB ${ }^{3,4,5}$, JEREMY GOVERMAN ${ }^{1,4,5}$, KASIE PAUL ${ }^{1,5}$ \\ JOHN YERXA ${ }^{1,5}$, RONALD G. TOMPKINS ${ }^{1,4,5}$ and ALAN J. FISCHMAN ${ }^{1,4,5}$ \\ Departments of ${ }^{1}$ Surgery, ${ }^{2}$ Pediatrics and ${ }^{3}$ Nuclear Medicine, Massachusetts General Hospital; \\ ${ }^{4}$ Harvard Medical School; ${ }^{5}$ Shriners Hospitals for Children, Boston, MA, USA
}

Received May 4, 2011; Accepted June 6, 2011

DOI: 10.3892/ijmm.2011.752

\begin{abstract}
After severe burn injury and other major traumas, glucose tolerance tests demonstrate delayed glucose disposal. This 'diabetes of injury' could be explained by insulin deficiency, and several studies have shown that soon after trauma (ebb phase) insulin concentrations are reduced in the face of hyperglycemia. After resuscitation of trauma patients (flow phase), $\beta$-cell responsiveness normalizes and plasma insulin levels are appropriate or even higher than expected, however, glucose intolerance and hyperglycemia persist. In the acute care setting, several approaches have been used for treating insulin resistance, including insulin infusion, propranolol and glucagon-like-peptide-1 (GLP-1). Recently, it was demonstrated that a tetrapeptide with antioxidant properties D-Arg-Dmt-Lys-Phe- $\mathrm{NH}_{2}$ (SS31), but not its inactive analogue Phe-D-Arg-Phe-Lys- $\mathrm{NH}_{2}$ (SS20) attenuates insulin resistance in mice maintained on a high fat diet. In this report the effects of SS31 and SS20 on burn-induced insulin resistance was studied in mice. Oral glucose tolerance tests (OGTT) were performed in 4 groups of 6 mice with thermal injury with or without pre-treatment with SS31 or SS20 and sham controls. In addition, biodistribution of ${ }^{18} \mathrm{FDG}$ was measured in burned mice with and without SS31 treatment and shams (subsets of these animals were also studied by $\mu \mathrm{PET}$ ). For comparison purposes, groups of 6 cold-stressed mice with and without SS31 treatment were also studied. The results of these studies demonstrate that SS31 but not SS20 ameliorated burn-induced insulin resistance. In addition, SS31 treatment resulted in marked reduction in the increased ${ }^{18} \mathrm{FDG}$ uptake by brown adipose tissue (BAT) in burned but not cold-stressed animals; suggesting that the stressors act by different mechanisms. Overall, these studies confirmed that SS31 can be used to
\end{abstract}

Correspondence to: Dr Alan J. Fischman, Shriners Hospitals for Children, 51 Blossom Street, Boston, MA 02114, USA

E-mail: aajjff@gmail.com

Key words: burn-injury, trauma, insulin-resistance, glucose-tolerance cold-stress, anti-oxidant oxidative stress, brown adipose tissue, oral glucose tolerance tests, $\mu \mathrm{PET},{ }^{18} \mathrm{FDG}, \mathrm{SS} 31, \mathrm{SS} 20$, reactive oxygen species reverse burn-induced insulin resistance and provide a firm pre-clinical basis for future clinical trials of SS31 for the treatment of insulin resistance in patients with burn injury.

\section{Introduction}

Maintenance of blood glucose levels is one of the most tightly regulated systems in the body, and although all cells require glucose, it is only available from exogenous sources in addition to hepatic and to a lesser extent renal cortical gluconeogenesis $(1,2)$. Since glucose cannot be stored in significant amounts except as glycogen in liver and muscle, transport into the cell by specific glucose transport proteins is essential for normal cellular function (3).

Insulin plays a critical role in maintaining normal levels of plasma glucose. Its secretion is stimulated when blood glucose levels rise and it stimulates uptake of glucose by skeletal muscle and other tissues via specific glucose transporter proteins and decreases glucose production by the liver (4). There are several key proteins in the insulin/glucose regulatory pathway cascade, including insulin receptor substrate 1 (IRS-1) and Akt1/Protein kinase $\mathrm{B} \alpha(\mathrm{Akt1} / \mathrm{PKB} \alpha)$ (5). When levels of insulin and glucose are abnormally high in the fasting state, in conditions such as type 2 diabetes, severe trauma and burn injury, a condition known as insulin resistance exists (6).

In the acute care setting, several approaches have been used for treating insulin resistance, including: insulin infusion (7), propranolol (8) and more recently, glucagon-like-peptide-1 (GLP-1) (9). Very recently, we demonstrated that simvastatin can also attenuate burn-induced insulin resistance (10). The use of insulin infusion is the most straightforward treatment, however, it can produce severe and potentially life-threatening hypoglycemia. Propranolol acts by inhibiting the effect of epinephrine $(11,12)$. The mechanism(s) by which GLP-1 reverses insulin resistance is more complex and involves both insulinotropic effects and direct inhibition of glucagon $(13,14)$. The mechanism for statin effects on insulin resistance are poorly defined but could be related to their anti-inflammatory actions.

Oxidative injury has been implicated in a wide variety of clinical disorders including, diabetes and burn injury. However, currently available antioxidants have not proven to be particularly effective for treating these conditions; possibly due to their 
inability to reach the relevant sites of free radical generation, especially if mitochondria are the primary source of reactive oxygen species (ROS). Oxidative damage to mitochondria has been shown to impair their function and lead to cell death via apoptosis and necrosis. Because dysfunctional mitochondria produce more ROS, a feed-forward loop is set up whereby ROS-mediated oxidative damage to mitochondria favors more ROS generation, resulting in a vicious cycle (15).

The recently developed Szeto-Schiller (SS) peptide antioxidants represent novel compounds for targeted delivery of antioxidants to the inner mitochondrial membrane (16). The most common feature of these peptides centers on alternating aromatic and basic amino acid residues (aromatic-cationic peptides). These peptides can scavenge hydrogen peroxide and peroxynitrite and inhibit lipid peroxidation. Their antioxidant action can be attributed to the presence of a dimethyltyrosine residue. D-Arg-Dmt-Lys-Phe- $\mathrm{NH}_{2}$ (SS31) is among the most potent ROS scavengers in this family of peptides. Since cells are highly permeable to SS31 (with a $3^{+}$charge) and mitochondria are the most electronegative cellular organelles, the peptide accumulates $>1,000$-fold at the inner mitochondrial membrane (17) where it scavenges ROS, and protects mitochondria from permeability transition, swelling, and cytochrome c release (17). It is believed that the ROS scavenging effect of SS31 is mediated via the dimethyl tyrosine residue in its sequence. Since the dimethyl tyrosine residue in SS31 is not present in Phe-D-Arg-Phe-Lys- $\mathrm{NH}_{2}$ (SS20) this peptide does not display ROS scavenging properties.

Among the SS peptides, SS31 has been most extensively studied and appears to be highly potent. Studies with isolated mitochondrial preparations and cell cultures have shown that SS31 can scavenge ROS, reduce mitochondrial ROS production, and inhibit the mitochondrial permeability transition (18). Excellent efficacy has also been demonstrated with animal models of myocardial ischemia-reperfusion injury (19), ischemic brain injury (20), neurodegeneration (21), islet isolation for transplantation (22), renal fibrosis (23) and 1-methyl4-phenyl-1,2,3,6-tetrahydropyridine (MPTP) neurotoxicity (24). It was recently demonstrated that SS31 but not its inactive analogue, SS20, can reverse insulin resistance that occurs in mice maintained on a high fat diet (25).

In this report, the effects of SS31 and SS20 on burninduced insulin resistance were studied with a murine model of burn injury.

\section{Materials and methods}

Materials. ${ }^{18} \mathrm{~F}$-labeled FDG was prepared by routine methods (26). SS31 and SS20 were purchased from Peptide 2.0 (Herndon, VA). Ethyl ether was purchased from Fisher Scientific Co. (Malvern, PA).

Burn injury in mice. Male CD1 mice weighing 25-28 g were purchased from Charles River Laboratories (Boston, MA). Full-thickness, non-lethal thermal injuries [30\% total body surface area (TBSA)] were produced, as previously described (27) using a protocol approved by the Subcommittee on Research Animal Care of the Massachusetts General Hospital. Briefly the mice were anesthetized with ether and their dorsal and ventral areas were shaved with animal hair clippers. Under ether anesthesia, the animals were placed in molds (acrylic plastic $1 / 4$ inch thick) exposing 30\% TBSA (dorsal plus ventral areas) followed by immersion of the dorsal area in a water bath at $90^{\circ} \mathrm{C}$ for $9 \mathrm{sec}$ and immersion of the ventral area in the same water bath for $4 \mathrm{sec}$. The animals were immediately resuscitated with saline $(50 \mathrm{ml} / \mathrm{kg}$ ) by intraperitoneal (i.p.) injection. The percent of TBSA was confirmed at necropsy by removal of the skin and measurement of the area burned vs. the total area of the pelt. Sham (control) mice, were anesthetized with ether, shaved, placed in molds, exposed to room temperature water and injected i.p. with saline. After the procedure, the animals were caged individually for the duration of the study without food, but with water provided ab libitum. Animals were monitored for post-treatment complications, including infection and failure of the normal healing process (granulation tissue formation and sloughing of injured skin); animals with either infection or abnormal healing were excluded from the study.

Effect of SS31 and SS20 on oral glucose tolerance tests (OGTT) performed in burn-injured and sham-treated mice. Burned mice treated with SS31 or SS20 and sham controls were studied at $24 \mathrm{~h}$ after injury. The doses of SS31 and SS20 were $4.0 \mathrm{mg} / \mathrm{kg}$, injected i.p. in the resuscitation fluid immediately after injury, $12 \mathrm{~h}$ and $24 \mathrm{~h}$ later by i.p. injection. After fasting overnight a $2 \mathrm{~g} / \mathrm{kg}$ glucose solution was administered via gavage. Glucose levels were determined on serial whole blood samples with a glucometer (Ascencia ${ }^{\circledR}$ Contour $^{\mathrm{TM}}$, Bayer Healthcare LLC, Mishawaka, IN). Areas under the plasma glucose curves (AUCs) were calculated using the trapezoidal rule. Initial glucose levels in the sham mice used in these studies never exceeded $100 \mathrm{mg} / \mathrm{dl}$.

Effect of SS31 and SS20 treatment on regional glucose metabolism. The biodistribution of ${ }^{18} \mathrm{FDG}$ was measured in groups of burned mice, burned mice treated with SS31 or SS20, and sham-treated controls. One day after burn injury as described above, SS31 or SS20 was injected i.p. $(4.0 \mathrm{mg} / \mathrm{kg})$ followed by fasting overnight with free access to water. On the following morning, the unanesthetized mice were injected with ${ }^{18} \mathrm{FDG}$ $(50 \mu \mathrm{Ci})$ via the tail vein. Approximately $60 \mathrm{~min}$ after tracer injection, the animals were sacrificed by cervical dislocation and complete biodistribution was measured. The results were calculated as the percentage of the injected dose per gram wet weight of tissue $(\% \mathrm{ID} / \mathrm{g})$. All results were expressed as mean \pm SEM. A subset of animals was injected with a larger dose of ${ }^{18} \mathrm{FDG}(\sim 500 \mu \mathrm{Ci})$ and the distribution of tracer was evaluated by $\mu$ PET.

Cold-stress in mice. To produce cold stress, mice were placed in a cold room at $4^{\circ} \mathrm{C}$ for $24 \mathrm{~h}$ with overnight fasting and access to water $a b$ libitum. The mice were housed three to a cage, the radiopharmaceutical $\left({ }^{18} \mathrm{FDG}\right)$ was administered on the following morning and biodistribution was measured as described above.

$\mu P E T$ imaging. Groups of burn-injured mice, burn-injured mice treated with SS31 or SS20 $(4.0 \mathrm{mg} / \mathrm{kg})$ and sham-treated controls were studied by ${ }^{18} \mathrm{FDG}-\mu$ PET. $\mu$ PET imaging was performed with a P $4 \mu$ PET camera (Concord Microsystems, Inc., Knoxville, $\mathrm{TN})$. One hour after intravenous injection of ${ }^{18} \mathrm{FDG}(\sim 500 \mu \mathrm{Ci})$ 


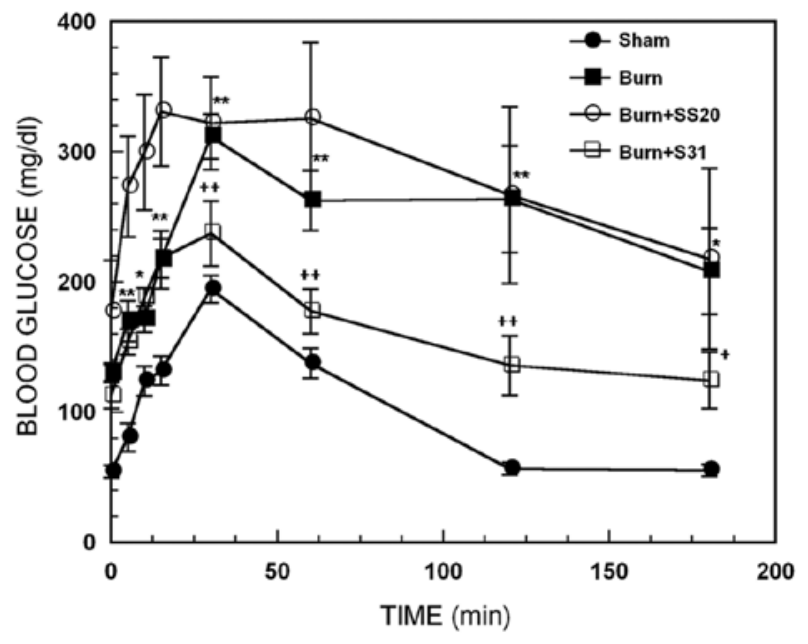

Figure 1. Effect of thermal injury and SS31 or SS20 treatment on oral glucose tolerance tests in mice; time dependence of blood glucose levels. Each value represents the mean \pm SEM for $6-12$ animals; ${ }^{* * *} \mathrm{P}<0.005$ and ${ }^{*} \mathrm{P}<0.05$ for burn vs. sham, ${ }^{++} \mathrm{P}<0.005$ and ${ }^{+} \mathrm{P}<0.05$ for burn $+\mathrm{SS} 31$ vs. burn alone.

via the tail vein without anesthesia, the mice were anesthetized, positioned and stabilized in the gantry of the PET camera and a 10 min image was acquired in list mode. The primary imaging characteristics of the $\mathrm{P} 4$ camera are in-plane and axial resolutions of $\sim 2 \mathrm{~mm}$ FWHM, 63 contiguous slices of $1.21 \mathrm{~mm}$ separation and a sensitivity of $\sim 650 \mathrm{cps} / \mu \mathrm{Ci}$. In all animals, the region from the head to the base of the tail was included in the $7.9 \mathrm{~cm}$ field of view of the camera. The PET images were reconstructed using an iterative algorithm maximum a posteriori (MAP) in a 256x256 matrix with zoom 4. Data for attenuation correction was measured with a rotating point source containing ${ }^{57} \mathrm{Co}$. All projection data were corrected for non-uniformity of detector response, dead time, random coincidences, and scattered radiation. The PET camera was cross-calibrated to a well scintillation counter by comparing the camera response from a uniform distribution of an ${ }^{18} \mathrm{~F}$ solution in a $5.0 \mathrm{~cm}$ cylindrical phantom with the response of a well counter to an aliquot of the same solution.

Statistical analysis. Statistical analyses were performed using 1-or 2-way ANOVA (as appropriate) and individual means were compared using Duncan's New Multiple range test. All results were expressed as mean \pm SEM. P-values of $<0.05$ were considered to be statistically significant.

\section{Results}

The glucose time-plasma concentration curves from OGTTs performed on mice with burn injury, burned mice treated with SS31 or SS20 and sham-treated controls are illustrated in Fig. 1. Two-way ANOVA demonstrated highly significant main effects of treatment, $\mathrm{F}_{3,160}=48.06 \mathrm{P}<0.00001$ and time, $\mathrm{F}_{7,160}=$ 9.90; $\mathrm{P}<0.00001$. Compared with sham-treated control animals, burn injury produced marked elevation and delayed normalization of blood glucose levels; baseline $(\mathrm{P}<0.0001), 5(\mathrm{P}<0.005)$, $10(\mathrm{P}<0.05), 15(\mathrm{P}<0.05), 30(\mathrm{P}<0.005), 60(\mathrm{P}<0.005), 120$ $(\mathrm{P}<0.005)$ and $180 \mathrm{~min}(\mathrm{P}<0.05)$. This elevation was significantly $(\mathrm{P}<0.05)$ reduced at 30,60 and 120 min by treatment

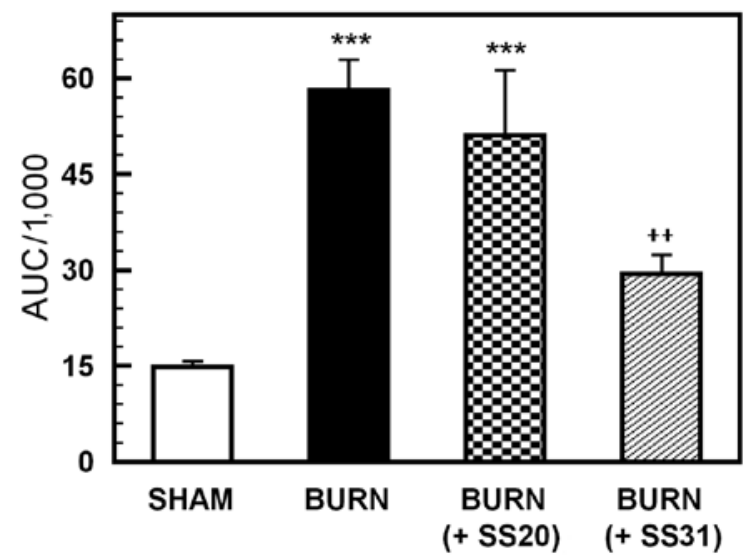

Figure 2. Areas under the plasma glucose curves (AUCs) of Fig. 1. Each value represents the mean \pm SEM for 6-12 animals. ${ }^{* * *} \mathrm{P}<0.0001$ for mice with burn injury alone or burn injury plus SS20 treatment vs. sham controls; ${ }^{+++} \mathrm{P}<0.001$ for burned mice treated with SS31 vs. mice with burn injury alone, burned mice treated with SS20 and sham controls.

of the burned animals with SS31. In contrast, treatment with SS20 did not reduce burn-induced elevations in glucose levels at any time point. In fact, although not statistically significant, at the early times (baseline to $15 \mathrm{~min}$ ) glucose levels tended to be higher in burned animals treated with SS20 compared with untreated burned animals.

Fig. 2 shows the AUCs calculated from the blood glucose curves in Fig. 1. One-way ANOVA demonstrated a highly significant main effect of treatment on AUC, $\mathrm{F}_{3,29}=20.15$; $\mathrm{P}<0.00001$. AUCs for burned animals and burned animals treated with SS20 were significantly greater than the values for SS31-treated animals and sham-treated controls $(\mathrm{P}<0.0001)$. The AUC of the SS31-treated group was significantly $(\mathrm{P}<0.001)$ reduced compared to burned animals and burned animals treated with SS20. Overall, the results of these studies clearly demonstrate that burn injury markedly elevates plasma levels of glucose (consistent with the results of previous studies) and that this effect is reduced by treatment with SS31 but not SS20.

The effects of treatment with SS31 on the burn injury and cold stress-induced changes in ${ }^{18} \mathrm{FDG}$ uptake by brown adipose tissue (BAT) in mice are shown in Fig. 3. ANOVA demonstrated a highly significant main effect of treatment, $\mathrm{F}_{4.45}=30.65 ; \mathrm{P}<0.0001$. Compared with sham-treated mice, animals with burn injury, cold stress and cold stress plus SS31 treatment had highly significant increases in ${ }^{18} \mathrm{FDG}$ uptake by BAT $(\mathrm{P}<0.0001)$. Cold-stress and cold stress plus SS31 treatment was associated with greater increases in ${ }^{18} \mathrm{FDG}$ uptake by BAT than burn injury alone or burn injury plus SS31 treatment $(\mathrm{P}<0.001)$. Burn plus SS31 treatment produced a significant $(\mathrm{P}<0.01)$ increase in ${ }^{18} \mathrm{FDG}$ uptake compared with shams. Treatment with SS31 produced a significant $(\mathrm{P}<0.05)$ reduction in ${ }^{18} \mathrm{FDG}$ uptake by BAT in burned animals. Surprisingly, SS31 treatment had no effect on the increase in ${ }^{18} \mathrm{FDG}$ uptake by BAT that was produced by cold stress. There were no significant effects of SS31 treatment on ${ }^{18}$ FDG uptake in any of the other tissues that were sampled.

$\mu P E T$ imaging. Representative ${ }^{18} \mathrm{FDG} \mu \mathrm{PET}$ images (sagittal slices) of a sham control mouse (left panel), a mouse with 


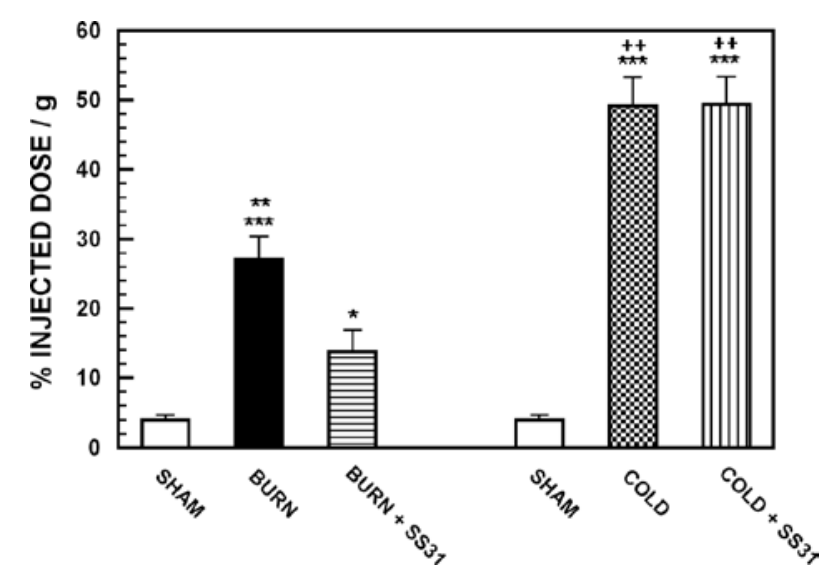

Figure 3. Effects of treatment with SS31 on burn injury and cold stressinduced changes in ${ }^{18} \mathrm{FDG}$ uptake by brown adipose tissue in mice. Each value represents the mean \pm SEM for 7 animals; ${ }^{* * * *} \mathrm{P}<0.0001$ for mice with burn injury alone, cold stress alone or cold stress plus SS31 treatment vs. sham controls; ${ }^{++} \mathrm{P}<0.001$ for mice with cold stress or cold stress plus SS31 treatment vs. mice with burn injury alone or burn injury plus SS31 treatment ${ }^{* *} \mathrm{P}<0.01$ for mice with burn injury alone vs. mice with burn injury plus SS31 treatment and sham controls; ${ }^{*} \mathrm{P}<0.05$ for mice with burn injury plus SS31 treatment vs. sham controls.

burn injury (middle panel) and a burn-injured mouse treated with SS31 (right panel) are illustrated in Fig. 4. ${ }^{18}$ FDG $\mu$ PET imaging demonstrated intense focal uptake at sites of BAT after burn injury. Uptake in BAT was so intense that it was associated with significant reductions in uptake by all other tissues, including brain. No such areas of intense ${ }^{18} \mathrm{FDG}$ uptake were observed in sham-treated control mice. In the mouse treated with SS31, there was reduced ${ }^{18} \mathrm{FDG}$ in BAT, and a partial normalization of ${ }^{18}$ FDG uptake in brain.

\section{Discussion}

Oxidative stress has been shown to have a role in insulin resistance associated with type 2 diabetes; based in part on the established role that ROS play in the endothelial, renal, and neural complications associated with hyperglycemia in late-stage diabetes (28). Numerous studies using nonspecific general antioxidant treatments have provided indirect evidence for a potential link between oxidative stress and insulin resistance (29-34). Recently, more direct evidence was provided by studies with cultured adipocytes using a mitochondrial-targeted strategy in which ROS were shown to play a causal role in the development of both TNF- $\alpha$ and glucocorticoid induced insulin resistance (35). However, the nature and molecular source(s) of ROS, the mechanisms governing their production, and their relevance to high-fat diet-induced insulin resistance (the most prevalent form of the disease) remain unknown.

In addition to providing energy to the cell, mitochondria are recognized as a site for the generation, dispensation, and removal of a number of intracellular signaling effectors, including hydrogen peroxide $\left(\mathrm{H}_{2} \mathrm{O}_{2}\right)$, calcium, and nitric oxide. The emission rate of $\mathrm{H}_{2} \mathrm{O}_{2}$ from mitochondria, which reflects the balance between the rate of electron leak/superoxide formation from the respiratory system and scavenging of $\mathrm{H}_{2} \mathrm{O}_{2}$ in the matrix, varies over a remarkably consistent range (36). Once in the cytosol, $\mathrm{H}_{2} \mathrm{O}_{2}$ can alter the redox state by either

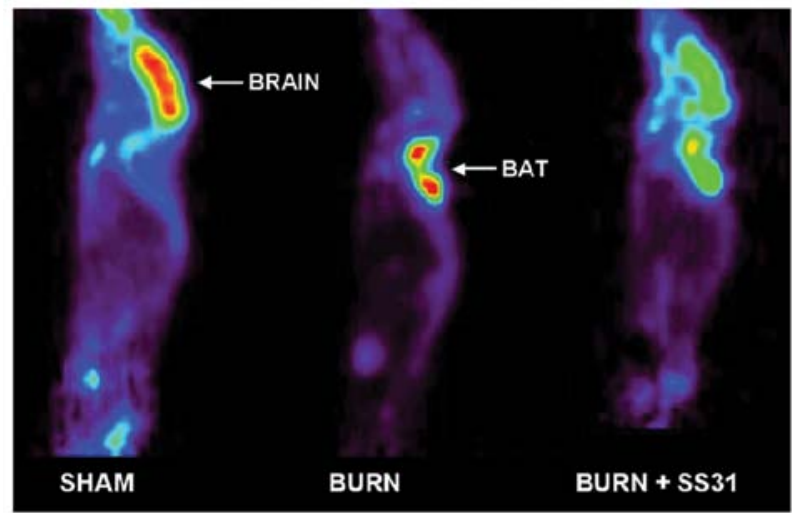

Figure 4. Representative ${ }^{18} \mathrm{FDG}-\mu \mathrm{PET}$ images of a sham-treated mouse (left panel), a mouse with burn injury (middle panel) and a mouse with burn injury that was treated with SS31 (right panel). ${ }^{18} \mathrm{FDG} \mu \mathrm{PET}$ imaging demonstrated intense focal uptake at sites of brown adipose tissue (BAT) after burn injury. Uptake in BAT was so intense that it was associated with significant reductions in uptake by all other tissues, including the brain. In the mouse treated with SS31, there was reduced ${ }^{18} \mathrm{FDG}$ in BAT, and a partial normalization of ${ }^{18}$ FDG uptake in the brain.

reacting directly with thiol residues in redox-sensitive proteins or shifting the ratio of reduced to oxidized glutathione (GSH/ GSSG); the main redox buffer of the cell. Thus, the rate at which $\mathrm{H}_{2} \mathrm{O}_{2}$ is emitted from mitochondria is considered an important index of mitochondrial function and modulator of the overall cellular redox environment (37). Two recent investigations have indicated that the rate of mitochondrial $\mathrm{H}_{2} \mathrm{O}_{2}$ emission is significantly greater when basal respiration is supported by fatty acid vs. carbohydrate-based substrates $(38,39)$, raising the possibility that mitochondrial $\mathrm{H}_{2} \mathrm{O}_{2}$ emission may be a primary factor in the etiology of insulin resistance. Anderson et al demonstrated that hydrogen peroxide production by mitochondria is linked to a high-fat-diet induced insulin resistance in both rodents and humans (25).

Burn injury is associated with oxidative stress (40-42) as well as insulin resistance $(8,9,28,29)$. Using the euglycemic insulin clamp technique it has been demonstrated that: i) maximal rate of glucose disposal is reduced in trauma patients, ii) the metabolic clearance rate of insulin is almost twice normal in these patients and iii) post-trauma insulin resistance appears to occur in peripheral tissues, probably skeletal muscle, and is consistent with a post-receptor effect $(31,43)$. Ikezu et al (44) demonstrated that burn injury results in impaired insulin-stimulated transport of $\left[{ }^{3} \mathrm{H}\right]$-2-deoxyglucose into rat soleus muscle strips in vitro. These investigations, as well as other studies from our laboratory (45) have also demonstrated that insulin stimulated phosphoinositide 3-kinase (PI 3-kinase) activity, which is pivotal for glucose transport in muscle by glucose transporter 4 (GLUT-4), is decreased by burn injury to rats as measured by its IRS-1 associated activity. These data are consistent with alterations in post receptor signaling following burn injury, which results in burn-induced insulin resistance. The present study was designed to determine whether SS31, which has been shown to have protective effects at the mitochondrial level, effects glucose clearance from the blood after burn injury or uptake of the glucose analogue ${ }^{18}$ FDG. The mechanism(s) by which burn injury in this mouse model alters these two parameters of glucose metabolism is not understood at this point. However, 
treatment with SS31 but not SS20 reduced the changes produced by burn injury. Whether this is related to changes in mitochondrial function in the burned mouse under these conditions is not clear. We have observed, however, that chronic treatment of burned rats with SS31 reduces the increased oxygen consumption produced by the burn injury $(46,47)$. One possibility is that the increased oxygen consumption produced by burn injury to rats is related to altered mitochondrial metabolism, which might be affected by SS31.

The surprising observation that the increase in ${ }^{18} \mathrm{FDG}$ uptake by BAT after burn injury is attenuated by treatment with SS31 whereas the peptide had no effect on the increase in ${ }^{18} \mathrm{FDG}$ produced by cold-stress has important implications. Since pre-treatment with propranolol reduces the increased ${ }^{18} \mathrm{FDG}$ uptake in BAT after cold stress in both animal models (48) and humans (49) and since that adrenalectomy reduces increased ${ }^{18} \mathrm{FDG}$ uptake in BAT after both burn injury and cold stress (50), the differential effects of SS31 suggest that the two stressors produce increased ${ }^{18} \mathrm{FDG}$ uptake by different mechanisms.

The observation that SS31-induced reductions in increased ${ }^{18}$ FDG uptake in BAT produced by burn injury closely parallel the results of OGTTs suggests that ${ }^{18} \mathrm{FDG}$-PET may be useful for evaluating new treatments for burn-induced insulin resistance and possibly for therapeutic monitoring of individual patients. This approach could have additional value for studying other types of insulin resistance such as in type 2 diabetes mellitus.

In conclusion, the results of these studies demonstrate that SS31, but not SS20, significantly attenuated burn-induced insulin resistance in mice. In addition, SS31 had major effects on the biodistribution of ${ }^{18}$ FDG. Most significantly, SS31 treatment resulted in marked reduction of ${ }^{18} \mathrm{FDG}$ uptake by BAT. These findings provide a firm pre-clinical basis for future clinical trials of SS31 for the treatment of insulin resistance in patients with burn injury and other conditions such as type 2 diabetes mellitus.

\section{Acknowledgements}

This study was supported in part by grants from the National Institutes of Health (2P50 GM21700-27A) and the Shriners Hospitals for Children.

\section{References}

1. Nordlie R, Foster J and Lange A: Regulation of glucose production by the liver. Ann Rev Nutr 19: 379-406, 1999.

2. Gerich J, Meyer C, Woerle H and Stumvoll M: Renal gluconeogenesis: its importance in human glucose homeostasis. Diabetes Care 24: 381-391, 2001.

3. Joost $\mathrm{H}$ and Thorens B: The extended GLUT-family of sugar/ polyol transport facilitators: nomenclature, sequence characteristics, and potential function of its novel members (Review). Mol Membr Biol 18: 247-256, 2001.

4. Saltiel A and Kahn R: Insulin signaling and the regulation of glucose and lipid metabolism. Nature 414: 799-806, 2001.

5. Jiang Z, Zhou Q, Coleman K, Chouinard M, Boese Q and Czech $\mathrm{M}$ : Insulin signaling through Akt/protein kinase B analyzed by small interfering RNA-mediated gene silencing. Proc Natl Acad Sci USA 100: 7569-7574, 2003.

6. Reaven G: The insulin resistance syndrome: definition and dietary approaches to treatment. Annu Rev Nutr 25: 391-406, 2005.

7. Pereira $C$ and Herndon D: the pharmacologic modulation of the hypermetabolic response to burn. Adv Surg 39: 245-261, 2005.
8. Herndon D, Dasu M, Wolfe R and Barrow R: Gene expression profiles and protein balance in skeletal muscle after beta-adrenergic blockage. Am J Physiol Endocrinol Metab 285: E783-E789, 2003.

9. Gleeson J, Berenbeim D and Gilkin R: Incretin mimetics: promising new therapeutic options in the treatment of type 2 diabetes. J Manag Care Pharm 11 (Suppl 7): S2-S13, 2005.

10. Bonab AA, Carter EA, Paul K, Kaneki M, Yu YM, Tompkins RG and Fischman AJ: Effect of simvastatin on burn-induced alterations in tissue specific glucose metabolism: implications for burn associated insulin resistance. Int J Mol Med 26: 311-316, 2010.

11. Deibert DC and Defronzo RA: Epinephrine-induced insulin resistance in man. J Clin Invest 65: 717-721, 1980.

12. Kusunoki M, Oshida Y, Iguchi A, Iida T, Suga T, Funado T, Sato Y, Kato K and Sakamoto N: Influence of sympatho-adrenal system on insulin sensitivity using the euglycemic clamp technique. Diabetes Res Clin Pract 17: 125-131, 1992.

13. Nauck MA,Kleine N, Orskov C,HoistJJ,Willms B and CreutzfeldtW: Normalization of fasting hyperglycaemia by exogenous glucagonlike peptide 1 (7-36 amide) in Type 2 (non-insulin-dependent) diabetic patients. Diabetologia 36: 741-744, 1993.

14. Nicolaus M, Bridle DL, Linke R, Woerle HJ and Schirra J: Endogenous GLP-1 regulates postprandial glycemia in humans: relative contributions of insulin, glucagon, and gastric emptying. J Clin Endocrinol Metab 96: 229-236, 2011.

15. Szeto HH: Mitochondria-targeted peptide antioxidants: novel neuroprotective agents. AAPS J 8: E521-E531, 2006.

16. Szeto HH: Cell-permeable, mitochondrial-targeted, peptide antioxidants. AAPS J 8: E277-E283, 2008.

17. Zhao K, Zhao GM, Wu D, Soong Y, Birk AV, Schiller PW and Szeto HH: Cell-permeable peptide antioxidants targeted to inner mitochondrial membrane inhibit mitochondrial swelling, oxidative cell death, and reperfusion injury. J Biol Chem 279: 34682-34690, 2004.

18. Szeto HH: Mitochondria-targeted cytoprotective peptides for ischemia- reperfusion injury. Antioxid Redox Signal 10: 601-619, 2008.

19. Cho J, Won K, Wu D, Soong Y, Liu S, Szeto HH and Hong MK: Potent mitochondria-targeted peptides reduce myocardial infarction in rats. Coron Artery Dis 18: 215-220, 2007.

20. Cho S, Szeto HH, Kim E, Kim H, Tolhurst AT and Pinto JT: A novel cell-permeable antioxidant peptide, SS31, attenuates ischemic brain injury by down-regulating CD36. J Biol Chem 282: 4634-4642, 2007.

21. Petri S, Kiaei M, Damiano M, Hiller A, Wille E, Manfredi G, Calingasan NY, Szeto HH and Beal MF: Cell- permeable peptide antioxidants as a novel therapeutic approach in a mouse model of amyotrophic lateral sclerosis. J Neurochem 98: 1141-1148, 2006.

22. Thomas DA, Stauffer C, Zhao K, Yang H, Sharma VK, Szeto HH and Suthanthiran M: Mitochondrial targeting with antioxidant peptide SS31 prevents mitochondrial depolarization, reduces islet cell apoptosis, increases islet cell yield, and improves posttransplantation function. J Am Soc Nephrol 18: 213-222, 2007.

23. Mizuguchi Y, Chen J, Seshan SV, Poppas DP, Szeto HH and Felsen D: A novel cell-permeable antioxidant peptide decreases renal tubular apoptosis and damage in unilateral ureteral obstruction. Am J Physiol Renal Physiol 295: F1545-F1553, 2008.

24. Yang L, Zhao K, Calingasan NY, Luo G, Szeto HH and Beal MF: Mitochondria targeted peptides protect against 1-methyl-4phenyl- 1,2,3,6-tetrahydropyridine neurotoxicity. Antioxid Redox Signal 11: 2095-2104, 2009.

25. Anderson EJ, Lustig ME, Boyle KE, Woodlief TL, Kane DA, Lin CT, Price JW, Kang L, Rabinovitch PS, Szeto HH, Houmard JA, Cortright RN, Wasserman DH and Neufer PD: Mitochondrial $\mathrm{H}_{2} \mathrm{O}_{2}$ emission and cellular redox state link excess fat intake to insulin resistance in both rodents and humans. J Clin Invest 119: 573-581, 2009.

26. Hamacher K, Coenen HH and Stock lin G: Efficient stereospecific synthesis of no-carrier-added 2-[ $\left.{ }^{18} \mathrm{~F}\right]$-fluoro- 2-deoxy-D-glucose using aminopolyether supported nucleophilic substitution. J Nucl Med 27: 235-238, 1986.

27. Pawlik TM, Carter EA, Bode BP, Fischman AJ and Tompkins RG: Central role of IL- 6 in burn induced stimulation of hepatic amino acid transport. Int J Mol Med 12: 541-548, 2003.

28. Evans JL, Goldfine ID, Maddux BA and Grodsky GM: Oxidative stress and stress-activated signaling pathways: a unifying hypothesis of type 2 diabetes. Endocr Rev 23: 599-622, 2002.

29. Bonnard C, Durand A, Peyrol S, Chanseaume E, Chauvin MA, Morio B, Vidal H and Rieusset J: Mitochondrial dysfunction results from oxidative stress in the skeletal muscle of diet-induced insulin-resistant mice. J Clin Invest 118: 789-800, 2008. 
30. Evans JL, Maddux BA and Goldfine ID: The molecular basis for oxidative stress-induced insulin resistances. Antioxid Redox Signal 7: 1040-1052, 2005.

31. Maddux BA, See W, Lawrence JC, Goldfine AL, Goldfine ID and Evans JL: Protection against ox idative stress-induced insulin resistance in rat L6 muscle cells by micromolar concentrations of $\alpha$-lipoic acid. Diabetes 50: 404-410, 2001.

32. Rudich A, Tirosh A, Potashnik R, Khamaisi M and Bashan N: Lipoic acid protects against oxidative stress induced impairment in insulin stimulation of protein kinase B and glucose transport in 3T3-L1 adipocytes. Diabetologia 42: 949-957, 1999.

33. Saengsirisuwan V, Kinnick TR, Schmit MB and Henriksen EJ: Interactions of exercise training and lipoic acid on skeletal muscle glucose transport in obese Zucker rats. J Appl Physiol 91: 145-153, 2001.

34. Saengsirisuwan V,Perez FR, Sloniger JA, Maier T and Henriksen EJ: Interactions of exercise training and \{alpha\}-lipoic acid on insulin signaling in skeletal muscle of obese Zucker rats. Am J Physiol Endocrinol Metab 287: E529-E536, 2004.

35. Houstis N, Rosen E and Lander ES: Reactive oxygen species have a causal role in multiple forms of insulin resistance. Nature 440: 944-948, 2006

36. Stone JR and Yang S: Hydrogen peroxide: a signaling messenger. Antioxid Redox Signal 8: 243-270, 2006.

37. Schafer FQ and Buettner GR: Redox environment of the cell as viewed through the redox state of the glutathione disulfide/ glutathione couple. Free Radic Biol Med 30: 1191-1212, 2001.

38. Anderson EJ, Yamazaki $\mathrm{H}$ and Neufer PD: Induction of endogenous uncoupling protein 3 suppresses mitochondrial oxidant emission during fatty acid-supported respiration. J Biol Chem 282: 31257-31266, 2007.

39. St-Pierre J,Buckingham JA, Roebuck SJ and Brand MD: Topology of superoxide production from different sites in the mitochondrial electron transport chain. J Biol Chem 277: 44784-44790, 2002.

40. Gurer A, Ozdogan M, Gokakin AK, Gomceli I, Gulbahar O, Arikok AT, Kulacoglu H and Aydin R: Tissue oxidative stress level and remote organ injury in two-hit trauma model of sequential burn injury and peritoneal sepsis are attenuated with $\mathrm{N}$-acetylcysteine treatment in rats. Ulus Travma Acil Cerrahi Derg 15: 1-6, 2009.
41. Foldi V, Csontos C, Bogar L, Roth E and Lantos J: Effects of fluid resuscitation methods on burn trauma induced oxidative stress. J Burn Care Res 30: 957-966, 2009.

42. Parihar A, Parihar MS, Milner S and Bhat S: Oxidative stress and anti-oxidative mobilization in burn injury. Burns 34: 6-17, 2008.

43. Black PR, Brooks DC, Bessey PQ, Wolfe RR and Wilmore DW: Mechanism of insulin resistance following injury. Ann Surg 196: 420-435, 1982.

44. Ikezu T, Okamoto T, Yonezawa K, Tompkins RG and Martyn JA: Analysis of thermal injury-induced insulin resistance in rodents, Implications of postreceptor mechanisms. J Biol Chem 272: 25289-25295, 1997.

45. Carter EA, Burks D, Fischman A, White M and Tompkins R: Insulin resistance in thermally-injured rats is associated with postreceptor alterations in skeletal muscle, liver and adipose tissue. Int J Mol Med 14: 653-658, 2004.

46. Yoh K, Carter EA, Lin F, Fischman AJ, Aikawa N, Tompkins RG and $\mathrm{Yu}$ YM: Mitochondria-targeted peptide attenuates the hypermetabolism after burn injury. J Burn Care 30: S106, 2009.

47. Yoh K, Carter EA, Lin F, Fischman AJ, Aikawa N, Tompkins RG and Yu YM: Mitochondria-targeted peptide attenulates the burn induced hypermetabolism by the down regulated UDP-1 expression in rat bown adipose tissue. J Burn Care 31: S104, 2010.

48. Tatsumi M, Engles JM, Ishimori T, Nicely O, Cohade C and Wahl RL: Intense ${ }^{18} \mathrm{~F}$-FDG uptake in brown fat can be reduced pharmacologically. J Nucl Med 45: 1189-1193, 2004.

49. Parysow O, Mollerach AM, Jager V, Racioppi S, San Roman J and Gerbaudo VH: Low-dose oral propranolol could reduce brown adipose tissue F-18 FDG uptake in patients undergoing PET scans. Clin Nucl Med 32: 351-357, 2007.

50. Carter E, McIntosh L, Cyr E, Tompkins R and Fischman A: Adrenalectomy suppresses FDG uptake by brown adipose tissue (BAT) after cold stress and acute burn, butnot dermal wounds. J Nucl Med 47: 344, 2006. 